\title{
99m Tc Radiotracers Based on Human GRP(18-27): Synthesis and Comparative Evaluation
}

\author{
Panteleimon J. Marsouvanidis ${ }^{1,2}$, Theodosia Maina ${ }^{1}$, Werner Sallegger ${ }^{3}$, Eric P. Krenning ${ }^{2}$, Marion de Jong ${ }^{2}$, \\ and Berthold A. Nock ${ }^{1}$ \\ ${ }^{1}$ Molecular Radiopharmacy, INRASTES, National Center for Scientific Research “Demokritos", Athens, Greece; ${ }^{2}$ Department of \\ Nuclear Medicine, Erasmus MC, Rotterdam, The Netherlands; and ${ }^{3}$ piCHEM, Graz, Austria
}

Gastrin-releasing peptide receptors (GRPRs) expressed on human tumors can serve as molecular targets for radiolabeled peptide analogs based on the frog tetradecapeptide bombesin (BBN). We have recently expanded this approach toward human GRP(18-27) sequences and introduced ${ }^{99 \mathrm{mTC}} \mathrm{T}$-demomedin $\mathrm{C}$, our first radiotracer based on GRP(18-27), showing favorable biologic characteristics during preclinical evaluation in rodents. We now present a series of $99 \mathrm{mTc}$-demomedin $\mathrm{C}$ analogs, generated by single-Gly ${ }^{24}$ or double-Gly ${ }^{24} / \mathrm{Met}^{27}$ substitutions in the peptide chain, and compare their performance in GRPR-positive in vitro and in vivo models. Methods: The SARNC $\left(\left[\left(\mathrm{N}_{4}\right) \mathrm{Gly}^{18}\right] \mathrm{GRP}(18-27)\right)$ analogs (SARNC2 $\mathrm{dAla}^{24}$, SARNC3 dAla ${ }^{24} / \mathrm{Nle}^{27}$, SARNC4 dAla ${ }^{24} / \mathrm{Leu}^{27}$, SARNC5 $\beta_{A l a}{ }^{24}$, and SARNC6 Sar ${ }^{24}$ ) were synthesized on the solid support and purified by high-performance liquid chromatography (HPLC). Competition binding experiments against [ ${ }^{125}$ I-Tyr $\left.{ }^{4}\right] B B N$ were conducted in GRPR-positive PC-3 cell membranes. Internal-

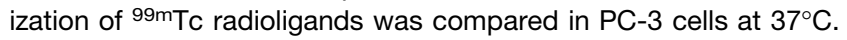
Metabolic stability was studied by HPLC analysis of blood samples collected $5 \mathrm{~min}$ after injection of radiopeptides in mice. Biodistribution was performed by injecting a ${ }^{99 m T C}$-SARNC bolus (185 kBq [ $5 \mu \mathrm{Ci}$ ], $100 \mu \mathrm{L}, 10 \mathrm{pmol}$ of peptide $\pm 40 \mathrm{nmol}$ of Tyr ${ }^{4}$-BBN: in vivo GRPR blockade) in severe combined immune deficient mice bearing PC-3 xenografts. Results: SARNCs bound to GRPR with high affinity (range of $50 \%$ inhibitory concentration $\left[\mathrm{IC}_{50}\right]$ values, $0.3 \mathrm{nM}$ [SARNC5] to $9.3 \mathrm{nM}$ [SARNC4]). ${ }^{99 m T C-S A R N C s ~ s p e c i f i c a l l y ~ i n t e r-~}$ nalized in PC-3 cells, with 99mTc-SARNC5 displaying the fastest internalization rate. ${ }^{99 m} \mathrm{Tc}-\mathrm{SARNCs}$ showed distinct degradation rates $\left(17 \%\right.$ [99mTc-SARNC3] to $>50 \%$ [ ${ }^{99 m}$ Tc-SARNC4] remaining intact). All ${ }^{99 m}$ Tc-SARNCs efficiently and specifically localized in GRPR-positive PC-3 xenografts in mice (4.4 percentage injected dose per gram [\%ID/g] [ ${ }^{99 m T c-S A R N C 4] ~ t o ~} 12.0 \% \mathrm{ID} / \mathrm{g}$ [ ${ }^{99 m T c}$ SARNC2] at $4 \mathrm{~h}$ after injection). $99 \mathrm{mTC}-\mathrm{SARNC6}$ displayed the highest tumor-to-nontumor ratios followed by 99mTc-SARNC2. Conclusion: This structure-activity relationship study has shown the impact of single-Gly ${ }^{24}$ or double-Gly ${ }^{24} / \mathrm{Met}^{27}$ substitutions in the $99 \mathrm{mTC}$-SARNC1 motif on key biologic parameters, including GRPR affinity, internalization efficiency, and in vivo stability, which eventually determine the pharmacokinetic profile of resulting radiopeptides. By revealing improved analogs, this study has strengthened the applicability perspectives of radioligands based on human GRP sequences in the detection and therapy of GRPRexpressing tumors in humans.

Received Dec. 18, 2012; revision accepted Apr. 12, 2013.

For correspondence contact: Berthold A. Nock, Molecular Radiopharmacy, INRASTES, NCSR "Demokritos", Ag. Paraskevi Attikis, GR-15310 Athens, Greece.

E-mail: nock_berthold.a@hotmail.com

Published online Sep. 5, 2013.

COPYRIGHT $\odot 2013$ by the Society of Nuclear Medicine and Molecular Imaging, Inc.
Key Words: tumor imaging; ${ }^{99 m} \mathrm{Tc}$ radiotracer; gastrin-releasing peptide; gastrin-releasing peptide receptor

J Nucl Med 2013; 54:1797-1803

DOI: 10.2967/jnumed.112.118695

A nalogs of the frog tetradecapeptide bombesin (BBN) have been exploited as molecular vehicles to direct diagnostic and therapeutic radionuclides to human primary and metastatic cancer (1-3). This approach relies on the high-density expression of gastrin-releasing peptide receptors (GRPRs) in many frequently occurring human cancers, such as prostate cancer, mammary carcinoma, or small cell lung cancer, as opposed to their lower abundance or lack of expression in surrounding healthy tissue (4-9). The success of radiolabeled BBN analogs to target GRPRexpressing cancer lesions in animal models and in humans has been partly attributed to their ability to internalize rapidly and massively into cancer cells after receptor binding. Internalization enhances trapping of the radiolabel into malignant cells, a process translating into higher diagnostic sensitivity or superior therapeutic efficacy depending on the radionuclide used for labeling $(10,11)$.

Following this rationale, we have previously reported on a series of tetraamine-functionalized ${ }^{99 \mathrm{~m}} \mathrm{Tc}$ radiotracers based on the full-length BBN and its truncated BBN(7-14) C-terminal octapeptide fragment, ${ }^{99 \mathrm{~m}} \mathrm{Tc}$-demobesin 3-6. These analogs indeed showed high affinity for the human GRPR, rapid internalization into human prostate cancer PC-3 cells, and effective targeting of PC-3 tumors xenografted in immunosuppressed mice, whereas their excretion from the body of mice was found to be dependent on peptide length or hydrophilicity of spacers introduced between metal-chelate and peptide chain (11). Urged by the lack of studies on radioligands based on human homologs of amphibian BBN, we have recently expanded our research activities toward human peptide sequences, such as the 27-mer GRP and its Cterminal decapeptide fragment GRP(18-27), otherwise referred to as neuromedin $\mathrm{C}(3,12)$. Hence, we have recently introduced ${ }^{99} \mathrm{~m}$ Tc-demomedin $\mathrm{C}$, formed by coupling an acyclic tetraamine chelator to the primary amine of Gly ${ }^{18}$ of GRP(18-27) to allow for labeling with ${ }^{99 \mathrm{~m}} \mathrm{Tc}$ (13). The new radioligand achieved high levels of specific uptake in PC-3 xenografts in severe combined immune deficient (SCID) mice while clearing more quickly from background tissues via the kidneys and into urine than the frog BBN-derived ${ }^{99 m}$ Tc-demobesin 3-6 $(11,13)$. Thus, the excellent pharmacokinetic profile of ${ }^{99 \mathrm{~m}} \mathrm{Tc}$-demomedin $\mathrm{C}$ has established that human 
GRP sequences can be exploited at least as successfully as their frog homologs to direct radionuclides on GRPR-positive lesions in vivo, providing a new platform for further structural interventions.

For this purpose, we now present 5 new analogs of the ${ }^{99 \mathrm{~m}} \mathrm{Tc}-$ demomedin C motif ( ${ }^{99 \mathrm{~m}}$ Tc-SARNC1) created by single-Gly ${ }^{24}$ or double-Gly ${ }^{24} / \mathrm{Met}^{27}$ substitutions to afford ${ }^{99 \mathrm{~m}} \mathrm{Tc}-\mathrm{SARNC} 2$ to ${ }^{99 \mathrm{~m}} \mathrm{Tc}-$ SARNC6. Specifically, Gly ${ }^{24}$ substitution by dAla (SARNC2), $\beta$ Ala (SARNC5), or Sar (SARNC6) aimed toward higher metabolic stability of resulting radioligands without compromising GRPR affinity. Similar modifications on BBN-based motifs have led to good GRPR affinity $(3,14)$, whereas a few BBN-based radioligands have shown a higher stability during incubation in mouse serum after replacement of the respective Gly ${ }^{11}$ in the frog tetradecapeptide chain (15). Two more analogs were further modified at position 27 with either Nle (SARNC3 $\mathrm{dAla}^{24} / \mathrm{Nle}^{27}$ ) or Leu (SARNC4 $\mathrm{dAla}^{24} / \mathrm{Leu}^{27}$ ), replacing the oxidation-susceptible Met in the native GRP(18-27) sequence. The effects of these modifications on key biologic parameters-such as GRPR affinity, internalization efficacy, metabolic stability, and pharmacokinetic profilewere studied in a head-to-head comparison using GRPR-expressing cell preparations and animal models and are reported herein. Results correlated with data reported for frog BBN-related radioligands, and conclusions on the applicability of new radiotracers in the scintigraphic detection of GRPR-positive lesions in patients are drawn.

\section{MATERIALS AND METHODS}

\section{Synthesis of SARNCs}

Synthesis of GRP(18-27) analogs was performed on an automated synthesizer (PSSM 8; Shimadzu) on a Tenta Gel S Ram resin (Rapp Polymere $\mathrm{GmbH}$ ) as solid support (capacity, $0.25 \mathrm{mEq} / \mathrm{g}$ of resin). The 9-fluorenylmethoxycarbonyl (Fmoc) amino acid derivatives were supplied by Orpegen Pharma and were protected with $\mathrm{N}^{\alpha}$ Fmoc and $\mathrm{N}^{\beta}$ Fmoc in the case of $\beta$ Ala. Trt side chain-protected His and Asn were used. The elongation was performed by the coupling of a 10-fold excess of Fmoc amino acid derivatives in the presence of 1-hydroxybenzotriazole, $N, N^{\prime}$-diisopropylcarbodiimide, and diisopropylamine in a mixture of $N, N$-dimethylformamide (DMF) and dichloromethane 90:10 v/v. After each coupling step, Fmoc deprotection was achieved with $30 \%$ piperidine in DMF. The assembled amino acid sequences were coupled with a 3 -fold excess of the tetra-Boc-protected tetraamine chelator ((Boc-N) $)_{4}$-COOH, $N, N^{\prime}, N^{\prime \prime}, N^{\prime \prime \prime}$-tetrakis-(tert-butoxycarbonyl)6-(carboxy)-1,4,8,11-tetraazaundecane), (benzotriazol-1-yloxy)-tripyrrolidinophosphonium hexafluorophosphate, and diisopropylamine in DMF on the resin. Cleavage of the conjugates from the solid support was achieved by treating the fully protected peptide chains with a mixture of trifluoroacetic acid (TFA), 1,2-ethanedithiol, thioanisol, and $\mathrm{H}_{2} \mathrm{O}$ in a ratio $90: 4: 4: 2 \mathrm{v} / \mathrm{v} / \mathrm{v} / \mathrm{v}$ at room temperature. After the resin was removed by filtration, the crude peptides were collected by precipitation with ice-cooled diethylether. Finally, the crude products were purified by reversed-phase high-performance liquid chromatography (RPHPLC) on an AKZO Nobel Kromasil Semi/Prep C18 column $(250 \times$ $20 \mathrm{~mm}$ ). Fractions containing the desired peptide were collected, and the solvent was removed by lyophilization. Analytic RP-HPLC data (from an Agilent system equipped with a Nucleosil-100 C18 column, $150 \times 4 \mathrm{~mm})$ and matrix-assisted laser desorption/ionization time-offlight mass spectrometry results (MALDI-TOF MS, Kompact Kraton Axima Analytic; Shimadzu) are summarized in Table 1.

\section{9mTc Labeling and Quality Control of 99mTc-SARNCs}

The lyophilized peptide analogs were dissolved in $50 \mathrm{mM}$ acetic acid/ $\mathrm{EtOH} 8 / 2 \mathrm{v} / \mathrm{v}$ to a final $1 \mathrm{mM}$ concentration and stored at $-20^{\circ} \mathrm{C}$ in $50-$ $\mu \mathrm{L}$ aliquots. Elution of a ${ }^{99} \mathrm{Mo} /{ }^{99 \mathrm{~m}} \mathrm{Tc}$ generator (Ultratechnekow; Tyco Healthcare) yielded ${ }^{99} \mathrm{mcO}_{4}{ }^{-}$, and labeling with ${ }^{99 \mathrm{~m}} \mathrm{Tc}$ was conducted, as previously described (13). Radioanalytic HPLC was performed on a chromatograph coupled to a 996 photodiode array ultraviolet detector (Waters) and a Gabi $\gamma$-detector (Raytest RSM Analytische Instrumente $\mathrm{GmbH})$. For analysis, a Waters RP8 XTerra $(5 \mu \mathrm{m}, 4.6 \times 150 \mathrm{~mm})$ cartridge column was eluted at a $1.0 \mathrm{~mL} / \mathrm{min}$ flow rate with the following gradient: $0 \% \mathrm{~B}$ to $40 \% \mathrm{~B}$ in $20 \mathrm{~min}$, where $\mathrm{A}=0.1 \%$ aqueous TFA and $\mathrm{B}=\mathrm{MeCN}$. Under these conditions, ${ }^{99} \mathrm{~m} \mathrm{TcO}_{4}{ }^{-}$elutes at $1.8 \mathrm{~min}$ and ${ }^{99 \mathrm{~m} T c-S A R N C s}$ with a retention time $\left(t_{\mathrm{R}}\right)$ more than $13 \mathrm{~min}$. For the detection of reduced hydrolyzed technetium $\left({ }^{99} \mathrm{mcO}_{2} \times \mathrm{H}_{2} \mathrm{O}\right)$, instant thin-layer chromatography (ITLC) was conducted on ITLC silica gel strips (Gelman Science), as previously described $(11,13)$.

\section{In Vitro Assays}

Human androgen-independent prostate adenocarcinoma PC-3 cells spontaneously expressing the GRPR (16) (LGC Promochem) were cultured as previously reported $(11,13)$ and were used in biologic assays. Competition binding experiments were conducted in PC-3 cell membranes as previously described (13). Tyr ${ }^{4}$-BBN (PSL GmbH) and ${ }^{125} \mathrm{I}$ (MDS Nordion, SA) were used for preparing [ $\left.{ }^{125} \mathrm{I}_{-} \mathrm{Tyr}^{4}\right] \mathrm{BBN}$. The latter served as a radioligand $(\sim 40,000 \mathrm{cpm}$ per assay tube, at a $50 \mathrm{pM}$ concentration) and GRP(18-27) (PeptaNova) as a reference compound; incubation at $22^{\circ} \mathrm{C}$ was applied for $45 \mathrm{~min}$ in an Incubator-Orbital Shaker (MPM Instruments SrI). Samples were measured for radioactivity in an automatic well-type $\gamma$-counter ([NaI(Tl)] crystal; Auto- $\gamma-5000$ series instrument [Canberra Packard]). The 50\% inhibitory concentration $\left(\mathrm{IC}_{50}\right)$ values were extracted from at least 3 independent experi-

TABLE 1

Analytic Data for SARNCs

\begin{tabular}{|c|c|c|c|c|c|}
\hline SARNC & Peptide conjugate & Percentage purity & $t_{\mathrm{R}}{ }^{*}(\min )$ & $\begin{array}{c}\text { Molecular weight } \\
\text { calculated, } \mathrm{m} / \mathrm{z}\end{array}$ & $\begin{array}{l}\text { Molecular weight }{ }^{\dagger} \\
\text { found, } \mathrm{m} / \mathrm{z}\end{array}$ \\
\hline SARNC1 & {$\left[\mathrm{N}_{4}^{0}\right] \mathrm{GRP}(18-27)$} & $\geq 95$ & 8.3 & $1,307.5[\mathrm{M}-\mathrm{H}]^{+}$ & $1,306.9[\mathrm{M}-\mathrm{H}]^{+}$ \\
\hline SARNC2 & {$\left[\mathrm{N}_{4}{ }^{0}, \mathrm{dAla}^{24}\right] \mathrm{GRP}(18-27)$} & $\geq 98$ & 8.3 & $1,321.6[\mathrm{M}-\mathrm{H}]^{+}$ & $1,321.9[\mathrm{M}-\mathrm{H}]^{+}$ \\
\hline SARNC3 & {$\left[\mathrm{N}_{4}{ }^{0}, \mathrm{dAla}^{24}, \mathrm{Nle}^{27}\right] \mathrm{GRP}(18-27)$} & $\geq 99$ & 9.9 & $1,305.5[\mathrm{M}-\mathrm{H}]^{+}$ & $1,305.6[\mathrm{M}-\mathrm{H}]^{+}$ \\
\hline SARNC4 & {$\left[\mathrm{N}_{4}^{0}, \mathrm{dAla}^{24}, \mathrm{Leu}^{27}\right] \mathrm{GRP}(18-27)$} & $\geq 98$ & 9.8 & $1,305.5[\mathrm{M}-\mathrm{H}]^{+}$ & $1,305.6[\mathrm{M}-\mathrm{H}]^{+}$ \\
\hline SARNC5 & {$\left[\mathrm{N}_{4}^{0}, \beta \mathrm{Ala}^{24}\right] \mathrm{GRP}(18-27)$} & $\geq 98$ & 9.1 & $1,321.6[\mathrm{M}-\mathrm{H}]^{+}$ & $1,321.4[\mathrm{M}-\mathrm{H}]^{+}$ \\
\hline SARNC6 & {$\left[\mathrm{N}_{4}{ }^{0}, \mathrm{Sar}^{24}\right] \mathrm{GRP}(18-27)$} & $\geq 99$ & 8.7 & $1,321.6[\mathrm{M}-\mathrm{H}]^{+}$ & $1,321.4[\mathrm{M}-\mathrm{H}]^{+}$ \\
\hline
\end{tabular}

${ }^{*}$ Nucleosil-100 C18 column $(150 \times 4 \mathrm{~mm})$ was eluted at flow rate of $1 \mathrm{~mL} / \mathrm{min}$ with linear gradient: $0.1 \%$ TFA in MeCN (10\%-90\% in $30 \mathrm{~min}$ ) and $0.1 \%$ aqueous TFA as complementary phase; runs were monitored by ultraviolet detection at $215 \mathrm{~nm}$.

${ }^{\dagger}$ Average mass. 


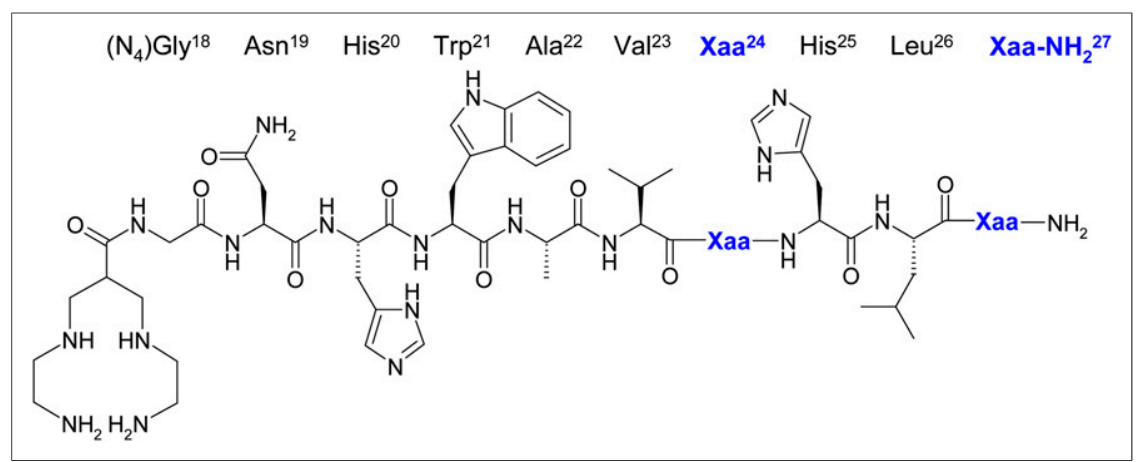

FIGURE 1. Chemical structures of SARNCs: SARNC1 (demomedin C motif)-Xaa ${ }^{24 /}$ $\mathrm{Xaa}^{27}=$ Gly ${ }^{24} / \mathrm{Met}^{27}$; SARNC2-dAla24/Met ${ }^{27}$; SARNC3-dAla ${ }^{24} / \mathrm{Nle}^{27}$; SARNC4-dAla ${ }^{24} /$ $\mathrm{Leu}^{27}$; SARNC5—BAla ${ }^{24} / \mathrm{Met}^{27}$; and SARNC6—-Sar ${ }^{24} / \mathrm{Met}^{27}$.

ments performed in triplicate using nonlinear regression according to a one-site model applying the PRISM 2 program (GraphPad Software).

For internalization, confluent PC-3 cells were seeded in 6-well plates $\left(\sim 1.0 \times 10^{6}\right.$ cells per well) $24 \mathrm{~h}$ before the experiment was conducted. Approximately $300,000 \mathrm{cpm}$ of test ${ }^{99 \mathrm{~m} T \mathrm{Tc}-S A R N C}$ (corresponding to $200 \mathrm{fmol}$ of total peptide in $150 \mu \mathrm{L}$ of $0.5 \%$ bovine serum albumin/phosphate-buffered saline) was added alone (total) or in the presence of $1 \mu \mathrm{M} \mathrm{Tyr}{ }^{4}-\mathrm{BBN}$ (nonspecific), and the experiment was performed following a published protocol (11). Results were calculated as percentage internalized per total added activity per million cells for each time point using Microsoft Excel and represent the average of at least 2 experiments performed in triplicate.

\section{Metabolism of ${ }^{99 m T C-S A R N C s ~}$}

99mTc-SARNC was injected as a $100-\mu \mathrm{L}$ bolus $(55.5-111 \mathrm{MBq}$ [1.5-3.0 mCi], $3 \mathrm{nmol}$ of total peptide) in the tail vein of male Swiss albino mice ( $30 \pm 5 \mathrm{~g}$, NCSR "Demokritos" Animal House Facility). Mice were anesthetized with ether, and blood $(0.5-1 \mathrm{~mL})$ was collected from the heart at exactly 5 min after injection. Blood samples were immediately transferred in prechilled polypropylene tubes containing ethylenediaminetetraacetic acid and placed on ice. Samples were prepared for analysis by HPLC as previously described (17). The Waters Symmetry Shield RP18 $(5 \mu \mathrm{m}, 3.9 \times 20 \mathrm{~mm})$ column was eluted at a flow rate of $1.0 \mathrm{~mL} / \mathrm{min}$ with the following gradient: $100 \%$ A to $90 \%$ A in 10 min and from $90 \%$ A to $60 \%$ for the next 60 min; for ${ }^{99 m}$ Tc-SARNC3 the gradient progressed from $100 \%$ A to $40 \% \mathrm{~A}$ within $60 \min (\mathrm{A}=0.1 \%$ aqueous TFA $[\mathrm{v} / \mathrm{v}]$ and $\mathrm{B}=\mathrm{MeCN})$. ITLC was performed in parallel using acetone as the eluent to detect traces of ${ }^{99} \mathrm{TcO}_{4}{ }^{-}$release $\left({ }^{99 m} \mathrm{TcO}_{4}{ }^{-} R_{\mathrm{f}}=0.9\right)$.

\section{Biodistribution of ${ }^{99 \mathrm{mTC}} \mathrm{TA}$-SANCs in PC-3 Xenograft- Bearing Mice}

An approximately $150-\mu \mathrm{L}$ bolus containing a suspension of approximately $1.5 \times 10^{7}$ freshly harvested human PC-3 cells in saline was subcutaneously injected in the flanks of female SCID mice (weight \pm $\mathrm{SD}, 15 \pm 3 \mathrm{~g}$; age at the day of arrival, $6 \mathrm{wk}$; NCSR "Demokritos" Animal House Facility). The animals were kept under aseptic conditions and 2-3 wk later developed well-palpable tumors at the inoculation site $(80-150 \mathrm{mg})$. On the day of the experiment, the selected ${ }^{99 m}$ Tc-SARNC was injected in the tail vein of mice as a $100-\mu \mathrm{L}$ bolus $(185 \mathrm{kBq}$ [5 $\mu \mathrm{Ci}$ ], $10 \mathrm{pmol}$ of total peptide; in saline/EtOH 9/1 $\mathrm{v} / \mathrm{v})$, and biodistribution for the 1-, 4-, and 24-h postinjection time intervals was conducted as previously described $(11,13)$. For in vivo GRPR blockade, a separate 4-h animal group additionally received excess $\mathrm{Tyr}^{4}$-BBN $(40 \mathrm{nmol})$. Biodistribution data were calculated as percentage injected dose per gram of tissue $(\% \mathrm{ID} / \mathrm{g})$ using the Microsoft Excel program and with the aid of suitable standards of the injected dose.
Statistical analysis using the unpaired 2tailed Student $t$ test was performed to compare values between control and the in vivo GRPR-blockade animal groups at $4 \mathrm{~h}$ after injection; $P$ values of less than 0.005 were considered statistically highly significant.

All animal experiments were performed in compliance with European and national regulations and after approval of protocols by national authorities.

\section{RESULTS}

\section{SARNC Ligands and 99mTC-SARNC Radioligands}

All 6 GRP(18-27) sequences were assembled on the solid support following typical Fmoc-protection methodology, and the Boc-protected $\mathrm{N}_{4^{-}}$ $\mathrm{COOH}$ chelator was attached to their $\mathrm{N}$ terminus in the last cycle. After release from the resin and removal of lateral protecting groups with TFA treatment, SARNCs (Fig. 1) were isolated by chromatographic methods in $95 \%$ purity or greater, as shown by analytic HPLC; MALDI-TOF spectra of the products were consistent with the expected formulae (Table 1).

${ }^{99 m}$ Tc-SARNC radioligands were obtained after 30-min incubation of respective SARNCs with ${ }^{99} \mathrm{mcO}_{4}{ }^{-}$and $\mathrm{SnCl}_{2}$ in the presence of citrate anions in alkaline aqueous medium, whereby complete incorporation of ${ }^{99 \mathrm{~m}} \mathrm{Tc}$ by the tetraamine framework was accomplished. Labeling yields greater than $98 \%$ were verified by combined ITLC and RP-HPLC methods in a specific activity of $18.5-37 \mathrm{MBq}(0.5-1 \mathrm{mCi}) / \mathrm{nmol}$ of SARNC.

\section{In Vitro Studies}

The binding affinities of SARNCs for the human GRPR were determined in PC-3 cell membranes. As shown in Figure 2, SARNCs were able to displace $\left[{ }^{125} \mathrm{I}_{-} \mathrm{Tyr}^{4}\right] \mathrm{BBN}$ from GRPR sites on PC-3 membranes in a monophasic and dose-dependent man-

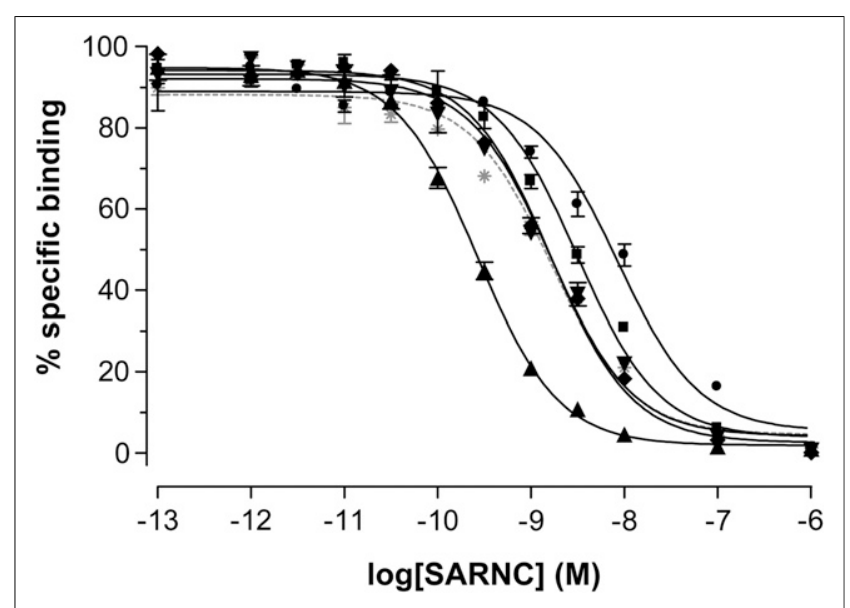

FIGURE 2. Displacement of $\left[{ }^{125} /-T y r^{4}\right] B B N$ from GRPR sites in PC-3 cell membranes by increasing concentrations of test peptide: $\checkmark=$ SARNC2 $\left(\mathrm{IC}_{50}=2.03 \pm 1.06 \mathrm{nM}\right) ; \mathbf{\square}=$ SARNC3 $\left(\mathrm{IC}_{50}=2.96\right.$ $\pm 1.33 \mathrm{nM}) ; \boldsymbol{\bullet}=$ SARNC4 $\left(\mathrm{IC}_{50}=9.29 \pm 3.55 \mathrm{nM}\right) ; \boldsymbol{\Delta}=$ SARNC5 $\left(\mathrm{IC}_{50}=0.28 \pm 0.02 \mathrm{nM}\right) ;$ and $\boldsymbol{\nabla}=$ SARNC6 $\left(\mathrm{IC}_{50}=1.78 \pm 0.32\right.$ $\mathrm{nM})$. Control: * $=\mathrm{GRP}(18-27)\left(\mathrm{IC}_{50}=1.66 \pm 0.12 \mathrm{nM}\right)$. Results represent average $I C_{50}$ values $\pm S D$ of 3 independent experiments performed in triplicate. 
ner. The calculated $\mathrm{IC}_{50}$ values were in the range of $0.28 \pm 0.02$ $\mathrm{nM}$ (SARNC5) to $9.29 \pm 3.55 \mathrm{nM}$ (SARNC4), with the $\mathrm{IC}_{50}$ for native GRP(18-27) determined at $1.66 \pm 0.2 \mathrm{nM}$. Single-Gly ${ }^{24}$ substitutions had a minor impact on receptor affinity as compared with the SARNC1 motif $\left(\mathrm{IC}_{50}=0.73 \pm 0.42 \mathrm{nM}\right.$, curve not included in the diagram), revealing a positive effect in the case of $\mathrm{AAla}^{24}$ replacement (SARNC5). Additional $\mathrm{Met}^{27}$ substitutions led to less affine conjugates, especially in the case of the $\mathrm{dAla}^{24}$ / $\mathrm{Leu}^{27}$ combination (SARNC4).

Internalization rates of ${ }^{99 \mathrm{~m}} \mathrm{Tc}-\mathrm{SARNCs}$ in PC-3 cells are compared in Figure 3. ${ }^{99 \mathrm{~m}} \mathrm{Tc}-\mathrm{SARNC} 5\left(\mathrm{BAla}^{24}\right.$ analog) showed the highest internalization efficiency, consistent with its superior receptor affinity. Slower internalization rates were exhibited by all other ${ }^{99 \mathrm{~m}}$ Tc-SARNCs in line with their respective affinities for the GRPR. As a result, the bis-Gly ${ }^{24} / \mathrm{Met}^{27}$-substituted analogs ${ }^{99 \mathrm{~m}} \mathrm{Tc}$-SARNC3 and ${ }^{99 \mathrm{~m}} \mathrm{Tc}-\mathrm{SARNC} 4$ displayed the poorest internalization efficacy among this series of analogs, but still approximately $80 \%$ of cell-associated radioactivity was internalized, consistent with an agonist profile. In all cases, internalization dropped below $1 \%$ in the presence of $1 \mu \mathrm{M} \mathrm{Tyr}^{4}$-BBN, indicating a GRPRmediated process.

\section{Stability and Biodistribution of ${ }^{99 m}$ Tc-SARNCs in PC-3 Xenograft-Bearing Mice}

The radiopeptide metabolism after entry into the bloodstream of mice was studied by RP-HPLC analysis of blood samples collected $5 \mathrm{~min}$ after injection. Representative radiochromatograms shown in Figure 4 reveal distinct radiometabolite patterns and degradation rates for individual ${ }^{99 \mathrm{~m} T c-S A R N C s .}{ }^{99 \mathrm{~m}} \mathrm{Tc}-$ SARNC1 shows a much faster in vivo degradation (30\% intact at 5 min after injection) than its previously reported in vitro breakdown in mouse serum at $37^{\circ} \mathrm{C}(65 \%$ intact at $30 \mathrm{~min})(13)$. Radioligand integrity was moderately prolonged after $\mathrm{Gly}^{24}$ substitution by dAla $(40 \%)$, BAla (32\%), and Sar $(42 \%)$ as compared with unmodi-

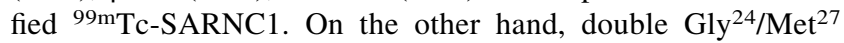
substitution produced the most stable $(>50 \%){ }^{99 \mathrm{~m}}$ Tc-SARNC4 $\left(\mathrm{dAla}^{24} / \mathrm{Leu}^{27}\right.$ combination) and the least stable radioligand

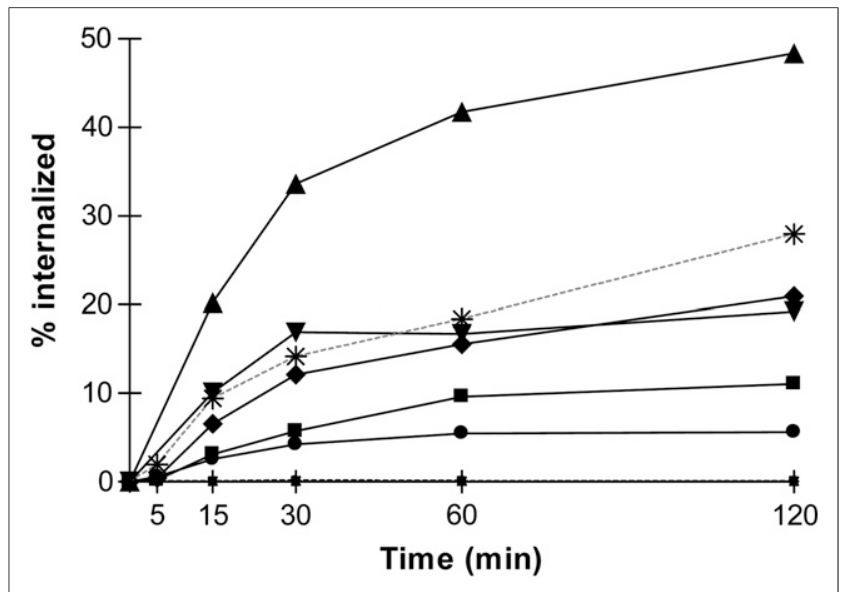

FIGURE 3. Comparative internalization of ${ }^{99 m T C-S A R N C s ~ i n ~ P C-3 ~}$ cells at $37^{\circ} \mathrm{C}$ as function of time: ${ }^{*}=99 \mathrm{mTC}-\mathrm{SARNC} 1 ;=99 \mathrm{mTC}-$ SARNC2; $\mathbf{\square}=$ 99mTc-SARNC3; $\bullet=99 \mathrm{mTC}-S A R N C 4 ; \boldsymbol{\Delta}=99 \mathrm{mTc}-$ SARNC5; and $\boldsymbol{\nabla}=99 \mathrm{mTC}-S A R N C 6$. Results represent percentage of specific internalized of total added radioactivity per million cells, and percentage of nonspecific internalization $(<1 \%$ in all cases in presence of $1 \mu \mathrm{M} \mathrm{Tyr}{ }^{4}-\mathrm{BBN}$ ) is indicated by empty bullets; assays have been performed twice in triplicate.
(17\%) ${ }^{99 \mathrm{~m}} \mathrm{Tc}-\mathrm{SARNC} 3\left(\mathrm{dAla}^{24} / \mathrm{Nle}^{27}\right.$ combination) within this group of analogs.

Cumulative biodistribution data of ${ }^{99 \mathrm{~m} T c-S A R N C s}$ in SCID mice bearing human GRPR-positive PC-3 xenografts are summarized in Table 2 ( ${ }^{99 \mathrm{~m}} \mathrm{Tc}-\mathrm{SARNC} 1$ included for comparison purposes (13) and $\left.{ }^{99 \mathrm{~m}} \mathrm{Tc}-\mathrm{SARNC} 2\right)$, Table $3\left({ }^{99 \mathrm{~m} T \mathrm{Tc}-S A R N C 3}\right.$ and

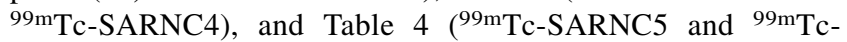
SARNC6). Results represent average \%ID/g values with SD at 1 , 4 , and $24 \mathrm{~h}$ after injection. All analogs showed a fast blood clearance. In all cases, radioactivity washed out from the body of mice via the kidneys rapidly into urine, with excretion via the hepatobiliary pathway playing a minor role.

All analogs were able to specifically target the GRPR-positive xenografts and mouse pancreas, as demonstrated by the significant reduction in the corresponding uptake values observed in the animals treated with excess $\mathrm{Tyr}^{4}$-BBN (in vivo GRPR blockade). The highest tumor uptake was exhibited by $99 \mathrm{~m}$ Tc-SARNC2 $\left(12.05 \pm 1.22 \% \mathrm{ID} / \mathrm{g}\right.$ at $4 \mathrm{~h}$ after injection), followed by ${ }^{99 \mathrm{~m}} \mathrm{Tc}-$ SARNC5 $\left(9.57 \pm 0.33 \% \mathrm{ID} / \mathrm{g}\right.$ at $4 \mathrm{~h}$ after injection) and ${ }^{99 \mathrm{~m}} \mathrm{Tc}-$ SARNC6 $(9.22 \pm 1.40 \% \mathrm{ID} / \mathrm{g}$ at $4 \mathrm{~h}$ after injection), which are the analogs that had undergone single substitutions at position 24 by dAla, BAla, or Sar, respectively. On the other hand, double$\mathrm{Gly}^{24} / \mathrm{Met}^{27}$-substituted ${ }^{99 \mathrm{~m} T c-S A R N C 3}$ and ${ }^{99 \mathrm{~m} T c-S A R N C 4}$ displayed much lower tumor uptake at the same time intervals $(\approx 4.5$ $\% \mathrm{ID} / \mathrm{g}$ at $4 \mathrm{~h}$ after injection). A similar trend was observed in pancreatic uptake, with less accumulation in the mouse pancreas of the twice $\mathrm{Gly}^{24} / \mathrm{Met}^{27}$-substituted members than in their Gly ${ }^{24}$ substituted counterparts. It is interesting to observe the massive pancreatic uptake of the $\beta \mathrm{Ala}^{24}$ analog versus the low pancreatic uptake of the $\operatorname{Sar}^{24}$ analog $(93.9$ vs. $14.5 \% \mathrm{ID} / \mathrm{g}$ at $4 \mathrm{~h}$ after injection, respectively) as opposed to their similar tumor uptake, revealing a most favorable tumor-to-background profile for ${ }^{99 \mathrm{~m}} \mathrm{Tc}-$ SARNC6.

\section{DISCUSSION}

In recent years, amphibian $\mathrm{BBN}$-based radioligands have been studied at length as molecular tools to diagnose and treat GRPR-positive cancer (e.g., prostate, breast, and lung) in humans $(1,2,9,12,15)$. In principle, this approach can be successful in targeting both primary and metastatic disease not only when the high density of GRPR expression in malignant lesions is maintained but also when the applied radioligands fulfill important prerequisites, such as availability in high specific activity, good receptor affinity and internalization ability, stability in the biologic milieu, and favorable pharmacokinetics to achieve high tumor-to-background ratios. Although native homologs of $\mathrm{BBN}$ do exist in humans, to date research efforts have been exclusively focused on frog BBN and its derivatives. BBN shows high binding affinity for 2 of the 3 human bombesin receptor (BBR) subtypes, the neuromedin $\mathrm{B}$ receptor $\left(\mathrm{NMBR}, \mathrm{BB}_{1} \mathrm{R}\right)$ and the GRPR $\left(\mathrm{BB}_{2} \mathrm{R}\right)$, but no affinity for the orphan $\mathrm{BB}_{3}$-receptor subtype $(12,14)$.

It has been shown that 2 mammalian homologs of BBN, the 27mer GRP and its C-terminal decapeptide fragment GRP(18-27) (otherwise known as neuromedin C), demonstrate high-affinity binding preferably to the human GRPR. Consequently, human GRP sequences can be exploited as molecular vectors, supplementary to the frog-derived motifs exclusively considered thus far, to tag diagnostic and therapeutic radionuclides on GRPR-expressing cancer. Following this rationale, we have recently introduced 


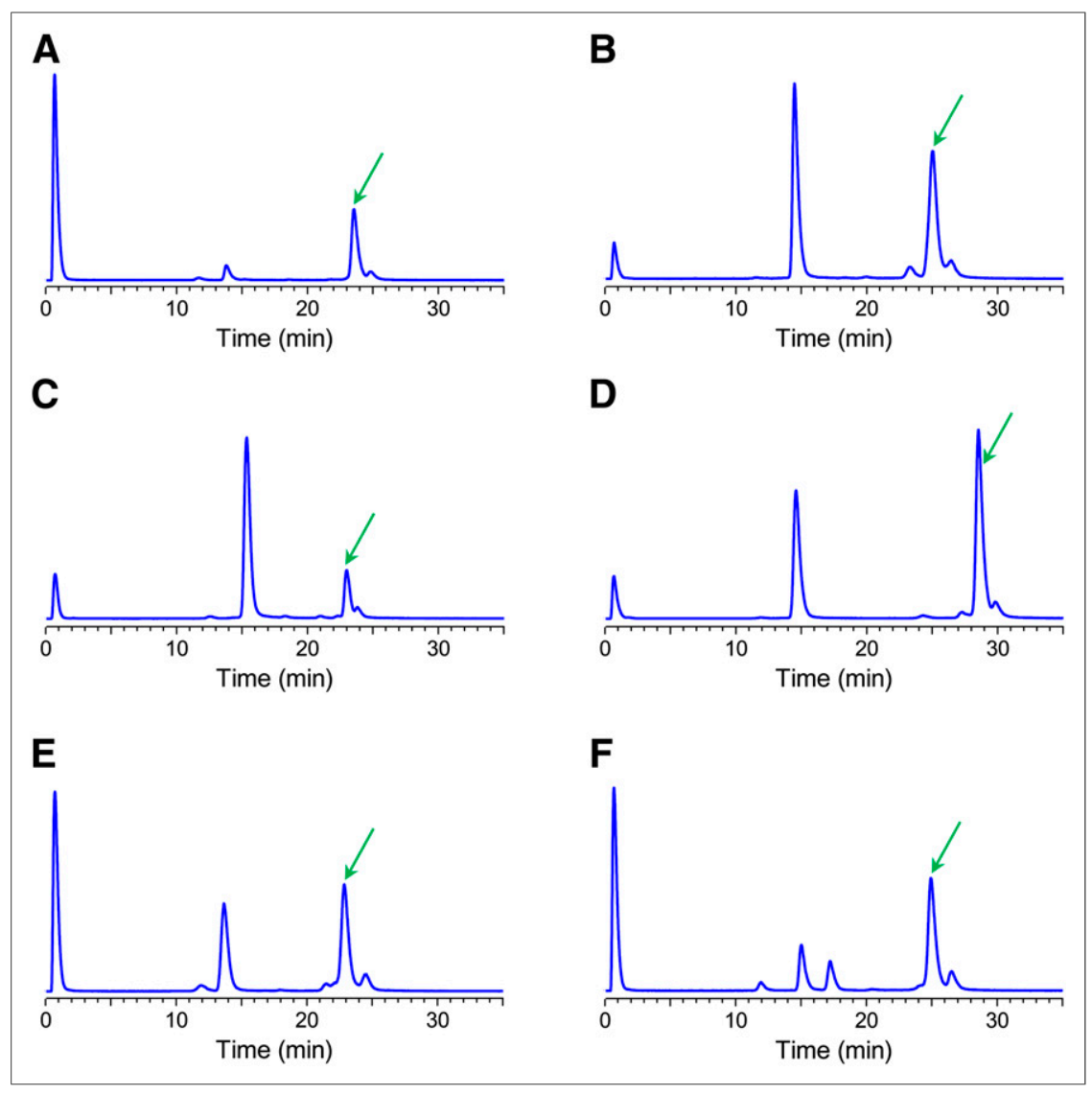

FIGURE 4. Radiochromatograms of blood samples collected 5 min after injection in mice for ${ }^{99 \mathrm{mTC}} \mathrm{T}-\mathrm{SARNC} 1$ (30\% intact, $\left.t_{\mathrm{R}}=23.6 \mathrm{~min}\right)(\mathrm{A})$, $99 \mathrm{mTc}-\mathrm{SARNC2}\left(40 \%\right.$ intact, $t_{\mathrm{R}}=$ $25.0 \mathrm{~min})(\mathrm{B}),{ }^{99 \mathrm{mTc}} \mathrm{T}-\mathrm{SARNC} 3\left(17 \%\right.$ intact, $\left.t_{\mathrm{R}}=23.0 \mathrm{~min}\right)(\mathrm{C}),{ }^{99 \mathrm{mTC}-S A R N C 4}(51 \%$ intact, $\left.t_{\mathrm{R}}=28.5 \mathrm{~min}\right)(\mathrm{D}),{ }^{99 \mathrm{mTc}} \mathrm{T}-\mathrm{SARNC5}\left(32 \%\right.$ intact, $\left.t_{\mathrm{R}}=22.9 \mathrm{~min}\right)(\mathrm{E})$, and ${ }^{99 \mathrm{~m} T \mathrm{c}-S A R N C 6}(42 \%$ intact, $\left.t_{R}=24.9 \mathrm{~min}\right)(\mathrm{F})$. Coinjection of samples with aliquots of labeling reaction solutions in HPLC revealed the position of parent radiopeptides (indicated by green arrow); HPLC conditions and gradient systems applied are given in text.

${ }^{99 m} \mathrm{Tc}$-demomedin $\mathrm{C}$, the first radioligand based on a human sequence, generated by coupling an acyclic tetraamine chelator to Gly ${ }^{18}$ of GRP(18-27) followed by labeling with ${ }^{99 \mathrm{~m}} \mathrm{Tc} .{ }^{99 \mathrm{~m}} \mathrm{Tc}-$ demomedin $\mathrm{C}$ displayed an excellent pharmacokinetic profile in mice bearing human PC-3 xenografts, characterized by high and specific uptake in the GRPR-positive xenografts and by a fast body clearance via the kidneys and the urinary tract (13). This in vivo profile was found to be superior to similarly modified ${ }^{99 m}$ Tc-demobesin 3-6, which are based on full tetradecapeptide $\mathrm{BBN}$ and its C-terminal nonapeptide fragment $\mathrm{BBN}(6-14)$ (11), especially with regards to longer tumor retention and faster body clearance.

Motivated by these promising results, we have now attempted additional structural modifications on the ${ }^{99 \mathrm{~m}}$ Tc-demomedin $\mathrm{C}$ motif, in an effort to further improve the biologic profile of resulting radioligands. Modifications comprised substitutions of $\mathrm{Gly}^{24}$ alone $\left(\mathrm{dAla}^{24}, \beta \mathrm{Ala}^{24}\right.$, or $\left.\mathrm{Sar}^{24}\right)$ or in combination with $\mathrm{Met}^{27}\left(\mathrm{dAla}^{24} / \mathrm{Nle}^{27}\right.$ or $\mathrm{dAla}^{24} / \mathrm{Leu}^{27}$ ) to afford SARNC2 to SARNC6, as depicted in Figure 1. The above effects on GRPR affinity, internalization, in vivo stability, and biodistribution of resulting compounds in $\mathrm{PC}-3$ tumorbearing mice compared under the same experimental settings are discussed herein.

Thus, single-Gly ${ }^{24}$ replacements by dAla or Sar in the demomedin C (SARNC1) motif slightly deteriorated affinity for the GRPR, whereas $\beta$ Ala substitution turned out to be more advantageous in terms of GRPR affinity. Further $\mathrm{Met}^{27}$ replacement leading to either $\mathrm{dAla}^{24} / \mathrm{Nle}^{27}$ or $\mathrm{dAla}^{24}$ / $\mathrm{Leu}^{27}$ analogs deteriorated GRPR affinity, with SARNC4 displaying the weakest binding affinity to the human GRPR (Fig. 2). These findings are in line with analogous effects on binding affinity for the human GRPR reported for similar modifications of frog BBN and BBN

TABLE 2

Biodistribution Data of ${ }^{99 m}$ Tc-SARNC1 and 99mTc-SARNC2 in PC-3 Xenograft-Bearing SCID Mice

\begin{tabular}{|c|c|c|c|c|c|c|}
\hline \multirow[b]{2}{*}{ Organ } & \multicolumn{3}{|c|}{ 99mTc-SARNC1 (13) } & \multicolumn{3}{|c|}{ 99mTc-SARNC2 } \\
\hline & $1 \mathrm{~h}$ & $4 \mathrm{~h}$ & $24 \mathrm{~h}$ & $1 \mathrm{~h}$ & $4 \mathrm{~h}$ & $24 \mathrm{~h}$ \\
\hline Blood & $0.64 \pm 0.37$ & $0.13 \pm 0.03(0.18 \pm 0.09)$ & $0.04 \pm 0.10$ & $1.48 \pm 0.28$ & $0.12 \pm 0.05(0.17 \pm 0.02)$ & $0.04 \pm 0.02$ \\
\hline Liver & $1.24 \pm 0.08$ & $1.00 \pm 0.14(1.64 \pm 0.12)$ & $0.47 \pm 0.15$ & $1.50 \pm 0.65$ & $0.68 \pm 0.17(1.10 \pm 0.29)$ & $0.32 \pm 0.06$ \\
\hline Heart & $0.34 \pm 0.04$ & $0.09 \pm 0.02(0.15 \pm 0.02)$ & $0.20 \pm 0.14$ & $0.71 \pm 0.20$ & $0.10 \pm 0.04(0.20 \pm 0.02)$ & $0.08 \pm 0.01$ \\
\hline Kidneys & $9.80 \pm 0.81$ & $6.81 \pm 0.89(7.22 \pm 1.24)$ & $2.58 \pm 0.38$ & $16.74 \pm 7.24$ & $7.77 \pm 1.59(3.66 \pm 0.99)$ & $2.88 \pm 0.43$ \\
\hline Stomach & $1.24 \pm 0.23$ & $0.68 \pm 0.10(0.70 \pm 0.40)$ & $0.63 \pm 0.18$ & $1.90 \pm 0.55$ & $0.66 \pm 0.22(0.30 \pm 0.10)$ & $0.46 \pm 0.22$ \\
\hline Intestines & $6.87 \pm 0.52$ & $6.96 \pm 0.42(2.53 \pm 0.66)^{\star}$ & $1.35 \pm 0.09$ & $8.17 \pm 1.04$ & $7.51 \pm 0.21(1.92 \pm 0.78)^{\star}$ & $2.62 \pm 0.14$ \\
\hline Spleen & $1.76 \pm 0.60$ & $1.12 \pm 0.36(1.86 \pm 1.26)$ & $0.82 \pm 0.31$ & $2.12 \pm 0.98$ & $1.47 \pm 0.07(3.98 \pm 2.80)$ & $0.81 \pm 0.19$ \\
\hline Muscle & $0.15 \pm 0.02$ & $0.03 \pm 0.00(0.04 \pm 0.01)$ & $0.04 \pm 0.02$ & $0.55 \pm 0.35$ & $0.05 \pm 0.01(0.04 \pm 0.01)$ & $0.06 \pm 0.02$ \\
\hline Lung & $0.81 \pm 0.04$ & $0.26 \pm 0.05(0.48 \pm 0.12)$ & $0.24 \pm 0.07$ & $2.58 \pm 1.45$ & $0.36 \pm 0.05(0.56 \pm 0.12)$ & $0.15 \pm 0.01$ \\
\hline Pancreas & $40.95 \pm 7.69$ & $34.38 \pm 5.49(0.59 \pm 0.04)^{\star}$ & $15.65 \pm 2.33$ & $56.01 \pm 4.07$ & $43.5 \pm 2.8(0.85 \pm 0.15)^{\star}$ & $17.78 \pm 2.16$ \\
\hline Tumor & $9.84 \pm 0.81$ & $6.36 \pm 0.85(0.41 \pm 0.07)^{\star}$ & $4.71 \pm 1.09$ & $18.55 \pm 2.84$ & $12.05 \pm 1.22(0.63 \pm 0.16)^{*}$ & $6.59 \pm 0.90$ \\
\hline
\end{tabular}

${ }^{*}$ Highly significant $(P<0.005)$ difference between blocked and unblocked animals (unpaired 2-tailed Student $t$ test).

Values in parentheses at $4 \mathrm{~h}$ after injection represent animals coinjected with $40 \mathrm{nmol}$ of $\mathrm{Tyr}^{4}$-BBN for in vivo GRPR blockade. Data presented are $\% \mathrm{ID} / \mathrm{g}$ tissue $\pm \mathrm{SD}, n=4$. 
TABLE 3

Biodistribution Data of 99mTc-SARNC3 and 99mTc-SARNC4 in PC-3 Xenograft-Bearing SCID Mice

\begin{tabular}{|c|c|c|c|c|c|c|}
\hline \multirow[b]{2}{*}{ Organ } & \multicolumn{3}{|c|}{ 99mTc-SARNC3 } & \multicolumn{3}{|c|}{ 99mTc-SARNC4 } \\
\hline & $1 \mathrm{~h}$ & $4 \mathrm{~h}$ & $24 \mathrm{~h}$ & $1 \mathrm{~h}$ & $4 \mathrm{~h}$ & $24 \mathrm{~h}$ \\
\hline Blood & $1.30 \pm 0.24$ & $0.11 \pm 0.05(0.19 \pm 0.01)$ & $0.07 \pm 0.01$ & $0.98 \pm 0.32$ & $0.09 \pm 0.02(0.72 \pm 0.60)$ & $0.06 \pm 0.02$ \\
\hline Liver & $1.04 \pm 0.16$ & $0.58 \pm 0.15(1.07 \pm 0.09)$ & $0.15 \pm 0.03$ & $0.93 \pm 0.27$ & $0.50 \pm 0.10(1.42 \pm 0.54)$ & $0.14 \pm 0.03$ \\
\hline Heart & $0.65 \pm 0.15$ & $0.10 \pm 0.01(0.27 \pm 0.05)$ & $0.07 \pm 0.01$ & $0.59 \pm 0.19$ & $0.07 \pm 0.01(0.48 \pm 0.41)$ & $0.10 \pm 0.03$ \\
\hline Kidneys & $9.98 \pm 0.82$ & $3.91 \pm 0.77(5.97 \pm 0.92)$ & $1.36 \pm 0.24$ & $7.65 \pm 1.22$ & $3.35 \pm 0.36(9.21 \pm 4.99)$ & $1.57 \pm 0.90$ \\
\hline Stomach & $2.04 \pm 0.60$ & $1.92 \pm 0.80(2.73 \pm 0.80)$ & $0.92 \pm 0.19$ & $1.51 \pm 0.59$ & $1.18 \pm 0.30(2.86 \pm 0.99)$ & $0.50 \pm 0.12$ \\
\hline Intestines & $4.27 \pm 0.64$ & $4.16 \pm 0.86(3.27 \pm 0.52)$ & $1.29 \pm 0.08$ & $3.08 \pm 0.58$ & $2.76 \pm 0.51(3.21 \pm 2.34)$ & $0.95 \pm 0.28$ \\
\hline Spleen & $1.27 \pm 0.20$ & $0.85 \pm 0.10(1.27 \pm 0.17)$ & $0.44 \pm 0.11$ & $1.07 \pm 0.27$ & $0.61 \pm 0.20(1.61 \pm 0.56)$ & $0.45 \pm 0.18$ \\
\hline Muscle & $0.28 \pm 0.07$ & $0.04 \pm 0.02(0.12 \pm 0.46)$ & $0.04 \pm 0.01$ & $0.22 \pm 0.08$ & $0.06 \pm 0.05(0.25 \pm 0.19)$ & $0.05 \pm 0.02$ \\
\hline Lung & $1.16 \pm 0.23$ & $0.22 \pm 0.06(0.54 \pm 0.07)$ & $0.08 \pm 0.01$ & $0.92 \pm 0.28$ & $0.17 \pm 0.05(0.80 \pm 0.45)$ & $0.10 \pm 0.03$ \\
\hline Pancreas & $16.26 \pm 2.93$ & $11.0 \pm 0.61(0.39 \pm 0.06)^{\star}$ & $3.20 \pm 0.37$ & $9.59 \pm 2.84$ & $5.65 \pm 1.16(0.49 \pm 0.17)^{\star}$ & $2.22 \pm 0.56$ \\
\hline Tumor & $6.97 \pm 1.36$ & $4.79 \pm 0.81(0.62 \pm 0.10)^{*}$ & $1.81 \pm 0.20$ & $7.51 \pm 1.90$ & $4.39 \pm 0.64(1.13 \pm 0.64)^{*}$ & $2.73 \pm 0.78$ \\
\hline
\end{tabular}

${ }^{*}$ Highly significant $(P<0.005)$ difference between blocked and unblocked animals (unpaired 2-tailed Student $t$ test).

Values in parentheses at $4 \mathrm{~h}$ after injection represent animals coinjected with $40 \mathrm{nmol}$ of Tyr ${ }^{4}$-BBN for in vivo GRPR blockade. Data presented are \%ID/g tissue $\pm \mathrm{SD}, n=4$.

(6-14) sequences $(3,14,15,18)$. Internalization efficacy of ${ }^{99 \mathrm{~m}} \mathrm{Tc}$ radioligands followed the same trend, with ${ }^{99 \mathrm{~m} T \mathrm{~T}-S A R N C 5}\left(\beta \mathrm{Ala}^{24}\right.$ replacement) displaying clearly superior internalization capacity at all time points, whereas ${ }^{99 \mathrm{~m} T c-S A R N C 4}\left(\beta_{\mathrm{Ala}^{24} / \mathrm{Leu}^{27} \text { combina- }}\right.$ tion) internalized poorly in $\mathrm{PC}-3$ cells at $37^{\circ} \mathrm{C}$ (Fig. 3).

Metabolic stability of ${ }^{99 \mathrm{~m}}$ Tc-SARNCs was studied by analysis of blood samples collected $5 \mathrm{~min}$ after injection. The degradation rate of unmodified ${ }^{99 \mathrm{~m}} \mathrm{Tc}-\mathrm{SARNC} 1$ in vivo was found to be much faster than during the in vitro incubation in mouse plasma reported previously, but a comparable pattern of radiometabolites was established. Similar observations between in vitro and in vivo degradation rates have also been reported for $\mathrm{BBN}$-based radioligands (e.g., ${ }^{177} \mathrm{Lu}-\mathrm{DO} 3 \mathrm{~A}-\mathrm{CH} 2 \mathrm{CO}-\mathrm{G}-4$-aminobenzoyl-Q-W-AV-G-H-L-M-NH2) $(19,20)$. Radiopeptides that had undergone single-Gly ${ }^{24}$ or double-Gly ${ }^{24} / \mathrm{Met}^{27}$ substitutions showed improvement of stability, except for ${ }^{99 \mathrm{~m} T c-S A R N C 3}\left(\beta \mathrm{Ala}^{24} / \mathrm{Nle}^{27} \mathrm{com}-\right.$ bination), which degraded much more rapidly after entry into the mouse bloodstream, even more so than unmodified ${ }^{99 \mathrm{~m}} \mathrm{Tc}$ -
SARNC1. Although neutral endopeptidase 24.11 has been reported to cleave the Trp-Ala and His-Leu bonds in the conserved C-terminal heptapeptide chain of native BBN and GRP peptides $(20,21)$, other enzymes may be implicated in their degradation as well $(18,20)$. Radiometabolite patterns from ${ }^{99 \mathrm{~m}} \mathrm{Tc}-\mathrm{SARNCs}$ differ from those derived from similarly modified but BBN-based ${ }^{99 m}$ Tc-demobesin 3-6 (11). It is apparent that more thorough studies are required to elucidate the degradation pathways of BBN-/GRP-based radioligands, instrumental for the rational design of truly in vivo robust analogs.

The biodistribution profile of ${ }^{99 \mathrm{~m}} \mathrm{Tc}-\mathrm{SARNCs}$ in mice bearing PC-3 xenografts, especially the uptake in the experimental tumors, seems to be a combined result of the above-described biologic features, namely of in vitro receptor affinity, internalization efficacy, and metabolic stability. Indeed, uptake in the human GRPR-positive xenografts among the mono-Gly ${ }^{24}$-substituted analogs is highest for ${ }^{99} \mathrm{~m}$ Tc-SARNC2, exhibiting improved stability (40\% intact) and good receptor affinity $\left(\mathrm{IC}_{50} \approx 2 \mathrm{nM}\right)$. The up-

TABLE 4

Biodistribution Data of 99mTc-SARNC5 and 99mTc-SARNC6 in PC-3 Xenograft-Bearing SCID Mice

\begin{tabular}{|c|c|c|c|c|c|c|}
\hline \multirow[b]{2}{*}{ Organ } & \multicolumn{3}{|c|}{ 99mTc-SARNC5 } & \multicolumn{3}{|c|}{ 99mTc-SARNC6 } \\
\hline & $1 \mathrm{~h}$ & $4 \mathrm{~h}$ & $24 \mathrm{~h}$ & $1 \mathrm{~h}$ & $4 \mathrm{~h}$ & $24 \mathrm{~h}$ \\
\hline Blood & $1.08 \pm 0.28$ & $0.13 \pm 0.02(0.23 \pm 0.05)$ & $0.04 \pm 0.05$ & $1.05 \pm 0.29$ & $0.06 \pm 0.03(0.35 \pm 0.37)$ & $0.03 \pm 0.01$ \\
\hline Liver & $1.39 \pm 0.07$ & $0.88 \pm 0.35(1.60 \pm 0.37)$ & $0.43 \pm 0.06$ & $1.00 \pm 0.15$ & $0.70 \pm 0.14(1.74 \pm 0.80)$ & $0.62 \pm 0.23$ \\
\hline Heart & $0.60 \pm 0.09$ & $0.13 \pm 0.02(0.21 \pm 0.02)$ & $0.13 \pm 0.01$ & $0.51 \pm 0.15$ & $0.07 \pm 0.01(0.25 \pm 0.20)$ & $0.07 \pm 0.07$ \\
\hline Kidneys & $20.49 \pm 2.70$ & $11.43 \pm 2.09(3.34 \pm 0.41)$ & $4.90 \pm 0.13$ & $8.09 \pm 1.31$ & $3.15 \pm 1.20(5.52 \pm 3.33)$ & $1.58 \pm 0.41$ \\
\hline Stomach & $2.70 \pm 032$ & $1.49 \pm 0.24(0.38 \pm 0.13)$ & $1.14 \pm 0.57$ & $0.75 \pm 0.26$ & $0.89 \pm 0.25(0.77 \pm 0.57)$ & $0.45 \pm 0.12$ \\
\hline Intestines & $11.64 \pm 2.08$ & $10.58 \pm 1.052 .34 \pm 0.46$ & $3.52 \pm 0.24$ & $3.85 \pm 0.48$ & $4.47 \pm 0.822 .65 \pm 1.45$ & $1.43 \pm 0.54$ \\
\hline Spleen & $3.38 \pm 0.98$ & $2.66 \pm 1.91(3.35 \pm 0.25)$ & $1.45 \pm 0.09$ & $2.03 \pm 0.62$ & $1.07 \pm 0.35(1.32 \pm 0.85)$ & $1.19 \pm 0.38$ \\
\hline Muscle & $0.26 \pm 0.04$ & $0.04 \pm 0.01(0.06 \pm 0.03)$ & $0.03 \pm 0.02$ & $0.27 \pm 0.09$ & $0.03 \pm 0.01(0.09 \pm 0.06)$ & $0.02 \pm 0.01$ \\
\hline Lung & $1.58 \pm 0.20$ & $0.43 \pm 0.05(1.07 \pm 0.29)$ & $0.36 \pm 0.14$ & $1.16 \pm 0.22$ & $0.44 \pm 0.12(1.23 \pm 0.16)$ & $0.32 \pm 0.04$ \\
\hline Pancreas & $131.58 \pm 17.87$ & $93.9 \pm 24.06(3.22 \pm 0.28)^{\star}$ & $37.91 \pm 3.01$ & $25.93 \pm 4.00$ & $14.50 \pm 1.34(0.50 \pm 0.14)^{\star}$ & $7.58 \pm 1.89$ \\
\hline Tumor & $18.25 \pm 5.11$ & $9.57 \pm 0.33(0.72 \pm 0.22)^{\star}$ & $6.26 \pm 1.17$ & $13.81 \pm 3.12$ & $9.22 \pm 1.40(0.60 \pm 0.23)^{\star}$ & $6.96 \pm 2.15$ \\
\hline
\end{tabular}

*Highly significant $(P<0.005)$ difference between blocked and unblocked animals (unpaired 2-tailed Student $t$ test).

Values in parentheses at $4 \mathrm{~h}$ after injection represent animals coinjected with $40 \mathrm{nmol}$ of Tyr ${ }^{4}$-BBN for in vivo GRPR blockade. Data presented are $\% \mathrm{ID} / \mathrm{g}$ tissue $\pm \mathrm{SD}, n=4$. 
take of ${ }^{99 \mathrm{~m}}$ Tc-SARNC5 $\left(\mathrm{IC}_{50} \approx 0.3 \mathrm{nM}\right)$ and ${ }^{99 \mathrm{~m}} \mathrm{Tc}-\mathrm{SARNC6}$ ( $>40 \%$ intact) is a compromise between affinity and stability, eventually resulting in comparable tumor values at all time intervals. Likewise, the doubly substituted members showing either poor stability ${ }^{99 \mathrm{~m}} \mathrm{Tc}-\mathrm{SARNC} 3,17 \%$ remaining intact at $5 \mathrm{~min}$ after injection) or low affinity $\left({ }^{99 \mathrm{~m}} \mathrm{Tc}-\mathrm{SARNC} 4, \mathrm{IC}_{50}>9 \mathrm{nM}\right)$ end up with similarly poor uptake in the xenografted tumors.

Seen together with background clearance rate, these results reveal a superior profile for ${ }^{99 \mathrm{~m} T c-S A R N C 6}$, especially as far as kidney, intestine, and pancreatic values are concerned (Tables 2

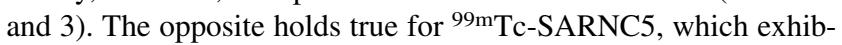
its the highest uptake in all the above physiologic tissues among the ${ }^{99 m}$ Tc-SARNC members (13). This finding is intriguing and may reflect differences in BBR-subtype selectivities between the $\mathrm{Sar}^{24}$ - and the $\beta \mathrm{Ala}^{24}$-substituted analog. Analogous substitution of Gly by $\beta$ Ala in GRP (at position 24) or in BBN (at position 11) sequences have led to a broader BBR-affinity profile $(3,14)$. The universal radiotracer ${ }^{125} \mathrm{I}-\left[\mathrm{dTyr}^{6}, \beta \mathrm{Ala}^{11}, \mathrm{Phe}^{13}, \mathrm{Nle}^{14}\right]$ $\mathrm{BBN}(6-14)$ is likewise substituted in the corresponding position 11 of the BBN-tetradecapeptide motif by $\beta A l a(22)$. An alternative explanation for this difference may be assigned to interspecies homology and tissue expression differences reported between the mouse and the human $\operatorname{GRPR}(14,15,23,24)$. These issues are currently addressed in detail by ongoing studies, and results will be instrumental in the design of the next generation of analogs based on either human or frog sequences.

\section{CONCLUSION}

The lack of studies on radioligands based on human GRP motifs for diagnosis and treatment of GRPR-positive cancer in humans has prompted us to recently introduce ${ }^{99 \mathrm{~m}} \mathrm{Tc}$-demomedin $\mathrm{C}$, the first GRP(18-27)-based radiotracer. We herein present a small library of GRP(18-27) analogs, likewise coupled to acyclic tetraamines to allow for ${ }^{99 \mathrm{~m}} \mathrm{Tc}$ labeling, that have undergone single $\left(\mathrm{Gly}^{24}\right)$ or double $\left(\mathrm{Gly}^{24} / \mathrm{Met}^{27}\right)$ substitutions (SARNC1-SARNC6) and compare their performance in GRPRpositive in vitro and in vivo models. This study has shown that analogs of highest receptor affinity (SARNC5- $\beta \mathrm{Ala}^{24}$ ) or metabolic stability (SARNC4-dAla ${ }^{24} / \mathrm{Leu}^{27}$ ) alone did not lead to the most favorable in vivo profile. A superior in vivo profile in terms of PC-3 tumor uptake and fast body clearance in mice was accomplished by ${ }^{99 m}$ Tc-SARNC6 ( $\mathrm{Sar}^{24}$ analog), which represents the best combination of GRPR affinity and metabolic stability within the group.

\section{DISCLOSURE}

The costs of publication of this article were defrayed in part by the payment of page charges. Therefore, and solely to indicate this fact, this article is hereby marked "advertisement" in accordance with 18 USC section 1734 . No potential conflict of interest relevant to this article was reported.

\section{REFERENCES}

1. Reubi JC. Peptide receptors as molecular targets for cancer diagnosis and therapy. Endocr Rev. 2003;24:389-427.
2. Maina T, Nock B, Mather S. Targeting prostate cancer with radiolabelled bombesins. Cancer Imaging. 2006;6:153-157.

3. Sancho V, Di Florio A, Moody TW, Jensen RT. Bombesin receptor-mediated imaging and cytotoxicity: review and current status. Curr Drug Deliv. 2011;8:79-134.

4. Markwalder R, Reubi JC. Gastrin-releasing peptide receptors in the human prostate: relation to neoplastic transformation. Cancer Res. 1999;59:1152-1159.

5. Gugger M, Reubi JC. Gastrin-releasing peptide receptors in non-neoplastic and neoplastic human breast. Am J Pathol. 1999;155:2067-2076.

6. Guinee DG Jr, Fishback NF, Koss MN, Abbondanzo SL, Travis WD. The spectrum of immunohistochemical staining of small-cell lung carcinoma in specimens from transbronchial and open-lung biopsies. Am J Clin Pathol. 1994;102:406-414.

7. Reubi JC, Korner M, Waser B, Mazzucchelli L, Guillou L. High expression of peptide receptors as a novel target in gastrointestinal stromal tumours. Eur J Nucl Med Mol Imaging. 2004;31:803-810.

8. Fleischmann A, Waser B, Reubi JC. Overexpression of gastrin-releasing peptide receptors in tumor-associated blood vessels of human ovarian neoplasms. Cell Oncol. 2007;29:421-433.

9. Nanda PK, Pandey U, Bottenus BN, et al. Bombesin analogues for gastrin-releasing peptide receptor imaging. Nucl Med Biol. 2012;39:461-471.

10. Breeman WA, Hofland LJ, de Jong M, et al. Evaluation of radiolabelled bombesin analogues for receptor-targeted scintigraphy and radiotherapy. Int J Cancer. 1999;81:658-665.

11. Nock BA, Nikolopoulou A, Galanis A, et al. Potent bombesin-like peptides for GRP-receptor targeting of tumors with ${ }^{99 \mathrm{~m} T c:}$ a preclinical study. J Med Chem. 2005;48:100-110.

12. Kroog GS, Jensen RT, Battey JF. Mammalian bombesin receptors. Med Res Rev. 1995; 15:389-417.

13. Nock BA, Cescato R, Ketani E, Waser B, Reubi JC, Maina T. $\left[{ }^{99 m} \mathrm{Tc}\right]$ demomedin $\mathrm{C}$, a radioligand based on human gastrin releasing peptide(18-27): synthesis and preclinical evaluation in gastrin releasing peptide receptor-expressing models. $J$ Med Chem. 2012;55:8364-8374.

14. Uehara H, Gonzalez N, Sancho V, et al. Pharmacology and selectivity of various natural and synthetic bombesin related peptide agonists for human and rat bombesin receptors differs. Peptides. 2011;32:1685-1699.

15. Zhang H, Abiraj K, Thorek DL, et al. Evolution of bombesin conjugates for targeted PET imaging of tumors. PLOS ONE. 2012;7:e44046.

16. Reile H, Armatis PE, Schally AV. Characterization of high-affinity receptors for bombesin/gastrin releasing peptide on the human prostate cancer cell lines PC-3 and DU-145: internalization of receptor bound ${ }^{125} \mathrm{I}-\left[\mathrm{Tyr}^{4}\right]$ bombesin by tumor cells. Prostate. 1994;25:29-38.

17. Tatsi A, Maina T, Cescato R, et al. [ ${ }^{111}$ In-DOTA]somatostatin-14 analogs as potential pansomatostatin-like radiotracers: first results of a preclinical study. EJNMMI Res. 2012;2:25.

18. Zhang H, Chen J, Waldherr C, et al. Synthesis and evaluation of bombesin derivatives on the basis of pan-bombesin peptides labeled with indium-111, lutetium-177, and yttrium-90 for targeting bombesin receptor-expressing tumors. Cancer Res. 2004;64:6707-6715.

19. Maddalena ME, Fox J, Chen J, et al. ${ }^{177} \mathrm{Lu}-\mathrm{AMBA}$ biodistribution, radiotherapeutic efficacy, imaging, and autoradiography in prostate cancer models with low GRP-R expression. J Nucl Med. 2009;50:2017-2024.

20. Linder KE, Metcalfe E, Arunachalam T, et al. In vitro and in vivo metabolism of Lu-AMBA, a GRP-receptor binding compound, and the synthesis and characterization of its metabolites. Bioconjug Chem. 2009;20:1171-1178.

21. Shipp MA, Tarr GE, Chen CY, et al. CD10/neutral endopeptidase 24.11 hydrolyzes bombesin-like peptides and regulates the growth of small cell carcinomas of the lung. Proc Natl Acad Sci USA. 1991;88:10662-10666.

22. Reubi JC, Wenger S, Schmuckli-Maurer J, Schaer JC, Gugger M. Bombesin receptor subtypes in human cancers: detection with the universal radioligand ${ }^{125} \mathrm{I}-\left[\mathrm{D}-\mathrm{Tyr}^{6}\right.$, ,beta-Ala $^{11}, \mathrm{Phe}^{13}, \mathrm{Nle}^{14}$ ]bombesin(6-14). Clin Cancer Res. 2002; 8:1139-1146.

23. Maina T, Nock BA, Zhang $H$, et al. Species differences of bombesin analog interactions with GRP-R define the choice of animal models in the development of GRP-R-targeting drugs. J Nucl Med. 2005;46:823-830.

24. de Jong M, Maina T. Of mice and humans: are they the same? Implications in cancer translational research. J Nucl Med. 2010;51:501-504. 